\title{
Prevalence of Hereditary Cancer Susceptibility Syndromes (HCSS) in Acute Lymphoblastic Leukemia (ALL): A Cross-Sectional Study in a Highly Consanguineous Population.
}

\author{
Sara Aslam ( $\nabla$ saraaslam702@gmail.com ) \\ University of the Punjab \\ Shabana NA \\ University of the Punjab \\ Mehboob Ahmed \\ University of the Punjab
}

\section{Research Article}

Keywords: Consanguinity, Hereditary cancer susceptibility syndrome (HCSS), Risk assessment, ACMG guidelines, acute lymphoblastic leukemia (ALL)

Posted Date: January 4th, 2021

DOl: https://doi.org/10.21203/rs.3.rs-133503/v1

License: (c) (i) This work is licensed under a Creative Commons Attribution 4.0 International License.

Read Full License 


\section{Abstract}

Background: Hereditary cancer susceptibility syndrome (HCSS) has been reported to impact cancer predisposition at an early age, therefore, identification of HCSS has found to be crucial for surveillance, managing therapeutic interventions and referring the patients and their families for genetic counselling. The aims of this study are to assess the prevalence of HCSS as hereditary leukemia and hematologic malignancy syndrome by using ACMG guidelines and to assess parental consanguinity as the criterion for referring patients for the genetic counselling.

Methods: A total of 300 acute lymphoblastic leukemia subjects were recruited from the Children's Hospital, Lahore, Pakistan during the period of December 2018 to September 2019. Structured selfreporting questionnaire based on family and medical history of the disease was utilized for the data collection.

Results: In our cohort, $60.40 \%$ of ALL patients were identified to have HCSS and among them $40.65 \%$ patients solely fulfil the criteria due to the presence of parental consanguinity. Parental consanguinity was shown to have protective impact on the onset at early age of disease $[O D=0.44(0.25-0.77), p$-value= $0.00]$ while family history of cancer increase the risk of cardiotoxicity [OD $=2.46(1.15-5.24), p-$ value $=0.02$ ]. Parental consanguinity in the population shows no significant impact on the family history of cancer and the number of relatives with cancer.

Conclusions: The higher prevalence of HCSS in Pakistani population is attributed to the presence of parental consanguinity in more than $50 \%$ of the patients when assessed through ACMG guidelines. Our study suggests revisiting ACMG guidelines for the criterion of parental consanguinity in the highly consanguineous population and formulating the score based criteria for the identification of inherited ALL for genetic counselling.

\section{Background}

According to the global cancer observatory 2018, Asia is the most leukemia burdened region in the world with an incidence rate of $48.7 \%$ and a mortality rate of $53.7 \%$ (1). In Pakistan, Acute Lymphoblastic Leukeima (ALL) is a predominant childhood cancer with an incidence rate of $20.8 \%$ as reported by the Punjab cancer registry 2017 (2). Remarkable progress has been observed in improving the survival rate of the acute lymphoblastic leukemia due to implementation of the risk-adapted therapy and with greater understanding of biological heterogeneity of the disease (3). However, the etiology of leukemia is still unknown, and the major cause reported for this cancer is the same as other cancers involving the interaction of environmental factors and genetic susceptibility (4-7). Hereditary cancer susceptibility syndromes include the predisposition to leukemia, often at an early age, caused by inherited mutations or polymorphisms. The identification of the HCSS aids in the cancer surveillance and screening, optimizing of the therapeutic response and advising the patient for genetic counselling to reduce the risk of cancer. The outcome of these practices helps to decline the incidence and morbidity rate of inherited leukemia 
among children $(8,9)$. It is estimated that $5-10 \%$ of the leukemia cases are attributed to the genetic susceptibility (10). However, Knapke et al., reported $29 \%$ of the survivors of childhood cancer to have HCSS and due to the presence of the familial history of cancer (11). The assessment of hereditary cancer susceptibility syndromes (HCSS) as hereditary leukemia and hematologic malignancy syndromes was found crucial for patients with familial history of cancer in first and second degree relatives (12).

Based on the evidence, early onset of cancer $(13,14)$, family history of cancer especially in a first and second degree of relatives (15), racial or ethnic differences (16) and consanguinity (17) are considered to be the major risk factors of hereditary cancer and are included in the various criteria established for the identification of HCSS, formulated by different consensus groups to identify the patients and families at risk of developing cancer and refer them for genetic counselling (18). The guidelines provided by the American College of Medical Genetics (ACMG) utilize consanguinity along with the familial history of cancer (19). Apart from one study conducted in the highly consanguineous population of Saudi Arabia, data on the contribution of consanguinity to hereditary leukemia and hematologic malignancies syndromes is are lacking. Consanguineous marriages are practiced around the world and reported to have severe implications if practiced in consecutive generations (20). In Europe and America, the rate of consanguinity is reported to be less than $1 \%$, and in Arab countries the rate is $20-50 \%(21)$, whereas in Pakistan, it is reported to be $60 \%$ (22). Among them, the most predominant degree of relatedness is the first cousins (20). In adults, constitutional MMR deficiency (CMMRD) syndrome has also been identified in the highly consanguinity population and is characterised by haematological malignancies and brain tumour however its prevalence in paediatric patients is underreported $(23,24)$.

The aim of the present study was to estimate the prevalence of HCSS in the acute lymphoblastic leukemia subjects in the Pakistani population to refer the patients for genetic counselling and to assess the role of consanguinity in the identification of HCSS in the highly consanguineous population.

\section{Materials And Methods}

\subsection{Study cohort and research ethics}

The cross sectional study was conducted at the University of the Punjab and the Research Ethics and Biosafety Committee approved the study protocol related to the data collection from the human subjects. The research was conducted accordance with the Declaration of Helsinki. The study population comprised of 300 acute lymphoblastic leukemia patients (Pre B-ALL and Pre T-ALL) of age 15 years or younger, diagnosed during December 2018 to September 2019. An informed consent was obtained from the patients or their guardian and data related to the personal information of patients and medical history of the disease was obtained. The exclusion criterion included any other type of leukaemia and patients seropositive for infectious diseases. The first degree relatives refer to the parents and siblings of the subject, second degree relative refer to the half-sibling, grandparents, uncle, aunt, niece and nephew and the third degree relatives refer to other cousins and great grandparents of the affected child.

\subsection{Data collection}


The data was collected from the Children's Hospital, Lahore, Pakistan by using subjective self-reporting questionnaire. The standardized face to face interviews were conducted to collect the data regarding family history of disease. Patient charts were consulted to obtain data related to the age of the patient, gender, number of primary cancer and associated disorders. The complete blood cell count, echocardiogram and ultrasound reports of the patients were consulted for the WBC count, hepatospleenomegaly and cardiotoxicity. The flow cytometry reports (FCM) were assessed for the presence of Pre T-ALL and Pre B-ALL markers. The patients who had positive family history were interviewed further regarding degree of family history with cancer and number of relatives with cancer.

\subsection{Assessment of HCSS and statistical analysis}

The assessment of HCSS among the target population was done according to the guidelines provided by American College of Medical Genetics (ACMG) and Genomics and the National Society of Genetic Counselors (NSGC) (19). It includes comprehensive personal and family history criteria that help in identification of high-risk individuals and referral for genetic counselling. The data were presented in the form of percentages and to assess the impact of the family history and familial consanguinity, Chisquare test was employed. The logistic regression model was used to assess the association of family history and familial consanguinity with ALL. All the models for the statistical analysis were expressed in the form of odds ratios (OR) and 95\% confidence interval (Cl).

\section{Results}

\subsection{Patient characteristics and identification of HCSS}

In the present study, three hundred patients of acute lymphoblastic leukemia (ALL) were recruited for the study and among them 2 (1.66\%) were excluded due to the presence of underlying disorders/syndromes i.e. Down syndrome (Fig. 1). The mean age at the time of diagnosis was $6.62 \pm 3.5$ and the male to female ratio was 2.59:1. Parental consanguinity was found in $151(50.67 \%)$ and familial history was present in 66 (22.14\%) patients. In our cohort, 257 (86.24\%) patients had Pre-BALL and 41 (13.75\%) patients had Pre-TALL. Only one patient had more than one primary cancers and it includes acute lymphoblastic leukemia with Ewing sarcoma. Hepatoslpeenomegaly was found in $35.90 \%$ patients while cardiotoxicity was observed in 34 (11.41\%) patients (Table 1). The consort diagram (Fig. 1) displays that $180(60.40 \%)$ patients meet the ACMG criteria and referral for genetic counselling. Among them 145 $(48.65 \%)$ have solely consanguineous parents, 29 (9.73\%) patients have family history of LS-associated cancer in 1 st and 2 nd degree relatives and $6(2.01 \%)$ patients have sibling with a childhood cancer. 
Table 1

Anthropometric characteristics and history of patients with ALL.

\begin{tabular}{|c|c|c|}
\hline Characteristics & Number & Percentage (\%) \\
\hline Mean age at diagnosis \pm SD & $6.62 \pm 3.5$ & \\
\hline \multicolumn{3}{|l|}{ Gender } \\
\hline Male & 215 & $72.14 \%$ \\
\hline Female & 83 & 27.85 \\
\hline \multicolumn{3}{|l|}{ Parental consanguinity } \\
\hline Yes & 151 & 50.67 \\
\hline No & 147 & 49.32 \\
\hline \multicolumn{3}{|l|}{ Family History of Cancer } \\
\hline Yes & 66 & 22.14 \\
\hline 1st degree & 6 & 9.09 \\
\hline 2nd degree & 47 & 71.21 \\
\hline 3rd degree & 20 & 30.30 \\
\hline No & 232 & 77.85 \\
\hline \multicolumn{3}{|l|}{ No of primary cancer } \\
\hline One & 299 & 99.66 \\
\hline Two & 1 & 0.34 \\
\hline \multicolumn{3}{|l|}{ Type of ALL } \\
\hline Pre B-ALL & 257 & 86.24 \\
\hline Pre T-ALL & 41 & 13.75 \\
\hline \multicolumn{3}{|l|}{ WBC count } \\
\hline$<50,000$ & 285 & 95.63 \\
\hline$\geq 50,000$ & 13 & 4.36 \\
\hline \multicolumn{3}{|l|}{ Hepatospleenomegaly } \\
\hline Yes & 107 & 35.90 \\
\hline No & 191 & 64.09 \\
\hline
\end{tabular}




Characteristics Number Percentage (\%)

\begin{tabular}{|lll|}
\hline Yes & 34 & 11.41 \\
No & 264 & 88.59 \\
\hline
\end{tabular} \\ 3.2. Impact of parental-consanguinity and history on the characteristics of ALL}

The parental consanguinity was observed in 151 indexed patients included in the study. Based on the age of patient, WBC count, hepatospleenomegaly and cardiotoxicity and sub-types of ALL the data were divided into two groups: consanguineous and non-consanguineous. The statistical analysis showed that the parental consanguinity had protective impact when compared with age of the patient. No significant association was observed with other variables. The patient with the two primary cancers has the history of parental consanguinity (Table 2). In our cohort, 66 (22.14\%) patients have family history of cancer in first, second and third degree relatives. The impact of familial history of cancer was also analyzed with the age of patient, WBC count, hepatospleenomegaly and cardiotoxicity observed during the time of treatment and types of ALL the data. Except cardiotoxicity, no significant association was observed with other variables. Familial history of cancer increase 2.46 times risk of the outcome of cardiotoxicity during the course of treatment (Table 3). 
Table 2

Impact of parental consanguinity on the characteristics and type of ALL patients with no associated disorder.

\begin{tabular}{|c|c|c|c|c|}
\hline Characteristics & $\begin{array}{l}\text { Parental } \\
\text { consanguinity }(\mathrm{n}= \\
151)\end{array}$ & $\begin{array}{l}\text { No parental } \\
\text { consanguinity }(n= \\
147)\end{array}$ & $\begin{array}{l}\text { Odds ratio } \\
(95 \% \mathrm{Cl})\end{array}$ & $\begin{array}{l}\mathrm{P} \text { - } \\
\text { value }\end{array}$ \\
\hline \multicolumn{5}{|l|}{ Age of the patient } \\
\hline$<10$ & $105(69.53 \%)$ & $123(83.67 \%)$ & \multirow{2}{*}{$\begin{array}{l}0.44 \\
(0.25- \\
0.77)\end{array}$} & \multirow[t]{2}{*}{$0.00 *$} \\
\hline$\geq 10$ & $46(30.46)$ & $24(16.32 \%)$ & & \\
\hline \multicolumn{5}{|l|}{ WBC count } \\
\hline$<50,000$ & $144(95.36 \%)$ & $141(95.91 \%)$ & \multirow{2}{*}{$\begin{array}{l}0.87 \\
(0.28- \\
2.66)\end{array}$} & \multirow[t]{2}{*}{0.82} \\
\hline$\geq 50,000$ & $7(4.63 \%)$ & $6(4.08 \%)$ & & \\
\hline \multicolumn{5}{|l|}{ Hepatospleenomegaly } \\
\hline Yes & $56(37.08 \%)$ & $51(38.77 \%)$ & \multirow{2}{*}{$\begin{array}{l}1.11 \\
(0.69- \\
1.78)\end{array}$} & \multirow[t]{2}{*}{0.66} \\
\hline No & $95(62.91 \%)$ & $96(65.30 \%)$ & & \\
\hline \multicolumn{5}{|l|}{ Cardiotoxicity } \\
\hline Yes & $15(9.93 \%)$ & $19(12.92 \%)$ & \multirow{2}{*}{$\begin{array}{l}0.74 \\
(0.36- \\
1.52)\end{array}$} & \multirow[t]{2}{*}{0.41} \\
\hline No & $136(90.06 \%)$ & $128(87.07 \%)$ & & \\
\hline \multicolumn{5}{|l|}{ Sub-type of ALL } \\
\hline Pre-BALL & $132(87.42 \%)$ & $125(85.03 \%)$ & \multirow{2}{*}{$\begin{array}{l}1.22 \\
(0.63- \\
1.36)\end{array}$} & \multirow[t]{2}{*}{0.55} \\
\hline Pre-TALL & $19(12.58 \%)$ & $22(14.96 \%)$ & & \\
\hline BCR-ABL translocation & $1(0.66 \%)$ & 0 & - & - \\
\hline $\begin{array}{l}\text { Two primary cancers in the } \\
\text { affected child }\end{array}$ & $1(0.66 \%)$ & 0 & - & - \\
\hline
\end{tabular}


Table 3

Impact of familial history on the characteristics and type of ALL patients with no associated disorder.

\begin{tabular}{|c|c|c|c|c|}
\hline Characteristics & $\begin{array}{l}\text { Familial history of } \\
\text { disease }(n=66)\end{array}$ & $\begin{array}{l}\text { No familial history of } \\
\text { disease }(n=232)\end{array}$ & $\begin{array}{l}\text { Odds ratio } \\
(95 \% \mathrm{Cl})\end{array}$ & $\begin{array}{l}\mathrm{P}- \\
\text { value }\end{array}$ \\
\hline \multicolumn{5}{|l|}{ Age of the patient } \\
\hline$<10$ & $49(74.24 \%)$ & $179(77.15 \%)$ & \multirow{2}{*}{$\begin{array}{l}0.85 \\
(0.45- \\
1.60)\end{array}$} & \multirow[t]{2}{*}{0.62} \\
\hline$\geq 10$ & $17(25.75 \%)$ & $53(22.84 \%)$ & & \\
\hline \multicolumn{5}{|l|}{ WBC count } \\
\hline$<50,000$ & $65(98.48 \%)$ & $220(94.82)$ & \multirow{2}{*}{$\begin{array}{l}3.54 \\
(0.45- \\
27.78)\end{array}$} & \multirow[t]{2}{*}{-} \\
\hline$\geq 50,000$ & $1(1.51 \%)$ & $12(5.17)$ & & \\
\hline \multicolumn{5}{|l|}{ Hepatospleenomegaly } \\
\hline Yes & $21(31.81 \%)$ & $86(37.06 \%)$ & \multirow{2}{*}{$\begin{array}{l}0.79 \\
(0.44- \\
1.41)\end{array}$} & \multirow[t]{2}{*}{0.43} \\
\hline No & $45(68.18 \%)$ & $146(62.93)$ & & \\
\hline \multicolumn{5}{|l|}{ Cardiotoxicity } \\
\hline Yes & $13(19.69 \%)$ & $21(21.98 \%)$ & \multirow{2}{*}{$\begin{array}{l}2.46 \\
(1.15- \\
5.24)\end{array}$} & \multirow[t]{2}{*}{$0.02 *$} \\
\hline No & $53(80.30 \%)$ & $211(90.94)$ & & \\
\hline \multicolumn{5}{|l|}{ Sub-type of ALL } \\
\hline Pre-BALL & $57(86.36 \%)$ & $200(86.20 \%)$ & \multirow{2}{*}{$\begin{array}{l}1.01 \\
(0.45- \\
1.24)\end{array}$} & \multirow[t]{2}{*}{0.86} \\
\hline Pre-TALL & $9(13.63 \%)$ & $32(13.79 \%)$ & & \\
\hline BCR-ABL translocation & $0(0.00)$ & $1(0.43 \%)$ & - & - \\
\hline $\begin{array}{l}\text { Two primary cancers in } \\
\text { the affected child }\end{array}$ & $0(0.00)$ & $1(0.43 \%)$ & - & - \\
\hline
\end{tabular}

\subsection{Family history association with parental consanguinity}

In our data, the ALL subjects with family history of cancer with parental consanguinity $(24.50 \%)$ were more than non-parental consanguinity (19.73\%) however, no significant impact of parental consanguinity on the family history of cancer was observed. We also assessed the impact of parental consanguinity on the degree of family history of cancer. The results of statistical analysis showed no significant impact of parental consanguinity on first, second, third and first and second degree of family history however, the odds ratio of first degree relative $[4.14(\mathrm{Cl}=0.45-37.60)]$ was higher as compared to the second 1.18 $[(0.62-1.20)]$, third [1.72 (0.60-4.90)], first and second degree relatives [1.31 (0.71-1.43)] with cancer. The association of the number of relatives of cancer with the parental consanguinity did not show any significant association as well ( $p$-value < 0.05) (Table 4). 
Table 4

Impact of parental consanguinity on family history of cancer and number of relatives with cancer.

\begin{tabular}{llll}
\multicolumn{2}{l}{ Parental consanguinity } & OR $(95 \% \mathrm{Cl})$ & P-value \\
\cline { 1 - 2 } & NES & \\
$(\mathrm{N}=151)$ & $(\mathrm{N}=147)$
\end{tabular}

Family history of cancer

\begin{tabular}{|c|c|c|c|c|}
\hline Yes & $37(24.50 \%)$ & $29(19.73 \%)$ & \multirow[t]{2}{*}{$1.32(0.76-1.29)$} & \multirow[t]{2}{*}{0.32} \\
\hline No & $114(75.49 \%)$ & $118(80.27 \%)$ & & \\
\hline First degree relatives & $4(10.81 \%)$ & $1(3.45 \%)$ & $4.14(0.45-37.60)$ & - \\
\hline Second degree relatives & $25(67.57 \%)$ & $22(68.96 \%)$ & $1.18(0.62-2.20)$ & 0.61 \\
\hline Third degree relatives & $10(27.03 \%)$ & $6(20.69 \%)$ & $1.72(0.60-4.90)$ & 0.30 \\
\hline First and second degree relatives & $29(78.37 \%)$ & $22(75.86 \%)$ & $1.31(0.71-2.43)$ & 0.38 \\
\hline \multicolumn{5}{|l|}{ Number of relatives with cancer } \\
\hline 1 & $141(93.37 \%)$ & $142(96.59 \%)$ & \multirow[t]{2}{*}{$0.49(0.16-1.48)$} & \multirow[t]{2}{*}{0.20} \\
\hline$\geq 1$ & $10(6.62 \%)$ & $5(3.40)$ & & \\
\hline
\end{tabular}

\section{Discussion}

This study assesses the prevalence of hereditary cancer susceptibility syndrome (HCSS) in childhood acute lymphoblastic leukemia patients and to our knowledge this is the first study conducted in the Pakistani population using the ACMG practice guidelines. We demonstrated that $60.40 \%$ of the paediatric ALL patients fulfils the criteria for the assessment of HCSS (Fig. 1). A previous study conducted in the highly consanguineous population of Saudi Arabia using the ACMG practice guideline has identified $40 \%$ cancer patients with HCSS that is lower than the Pakistani population (12). This may be due to the fact that our study population focus only the childhood ALL while the study subjects in Jastaniah and coworkers, comprise of all the cancers diagnosed in multi-institutions in Saudi Arabia. Knapke and coworkers also reported $29 \%$ childhood cancer survivors to meet the criteria for the HCSS however different criteria were established for the assessment of HCSS that comprise of medical and familial history of cancer (11).

ACMG guidelines limits the parental consanguinity for the leukemia and brain tumours as these cancers have been reported to be associated with Constitutional mismatch repair deficiency (CMMRD) syndrome (25). In our cohort, $48.65 \%$ patients with HCSS were referred to the genetic counselling solely due the presence of parental consanguinity (Fig. 1). We also assessed association between parental consanguinity and family history with anthropometric characteristics, chemotherapy related toxicity and subtype of ALL. The results showed that age at the diagnosis of disease, hepatospleenomegaly and 
subtype of ALL was comparable among consanguineous and non-consanguineous patients however consanguineous showed significantly protective impact age at diagnosis of disease (Table 2). This is in concordance with the previous studies performed in highly consanguineous populations of Middle East that suggests that consanguinity confers protective effect to the development of the adult cancers at an early age (26-28). In the previous studies, different germ line genetic variations have been associated with the chemotherapy related cardiotoxicity $(29,30)$. We also found that cardiotoxicity to be comparable in patients having family history of cancer when compared with patients without family history of cancer and it showed that the familial history of cancer asserts increase risk of toxicity in ALL patients (Table 3). At present, the outcome of chemotherapy related toxicities has not been utilized by the ACMG guidelines as a criterion for the assessment of HCSS and our study suggests it to be factored into the assessment guidelines.

It is interesting that despite high consanguinity (50.67\%) in the population only 29 patients have shown to have of family history of cancer in $1 \mathrm{st}$ and 2 nd degree relatives moreover, $2(0.66 \%)$ patients have shown to have associated syndrome that is Down syndrome (Table 1$)$. In our cohort, only 1 (0.34) patient has second primary cancer. This reflects that HCSS or CMMRD is not much prevalent in our population otherwise these numbers would be higher. It may also be attributed due short the follow up duration of the patient. It can also be conclude that high frequency of consanguinity alone does not increase the risk of family history and the results were consistent when compared with the $1 \mathrm{st}, 2 \mathrm{nd}$ and $3 \mathrm{rd}$ degree of relatedness and number of relatives with cancer (Table: 4).

The results of our study are in concordance with the recommendations made by the Jastaniah et al. that suggest the score based criteria based on multifactorial genetic risks factors, the toxicology profile and physical features along with the personal and family history of cancer for the identification of HCSS especially for the high consanguineous populations (12). Genetic evaluation of large number of patients may not be feasible especially for developing country therefore in order to manage the resources "Genetic testing for all children with cancer" approach is needed to be re-evaluated. To assess the prevalence of the germ line mutations or variation related to hereditary cancer susceptibility the population based screening using high throughput techniques is needed to be performed. The possible limitations of the study include self-reporting bias related to the family history of disease and lack of availability of pathology reports of the relatives having history of cancer. The self-reporting bias was reduced by using a structured standardized self-reporting questionnaire conducted by the trained individual. Various studies have been performed to analyse the validity of self-reporting of family history of cancer and found that the sensitivity ranges from 0.78 to $0.90(31,32)$ moreover the recall bias is expected to be lowered due to the extended family support system of Pakistani culture.

\section{Conclusion}

Results of our cross-sectional study in acute lymphoblastic leukeima have identified $60.40 \%$ patients with hereditary cancer susceptibility syndrome (HCSS) by using ACMG guidelines. Parental consanguinity was the leading criteria for the identification however the findings of our study underscore revisiting this 
criterion especially in highly consanguineous populations. Population based screening of mutations and variation related to hereditary susceptibility is needed to be performed in Pakistani population that aims to contribute to the development of genetic-screening tool for the early assessment of cancer.

\section{Declarations}

Ethics approval and consent to participate: The research was conducted accordance with the Declaration of Helsinki. The consent to participate in the study was taken from the guardians of patients as the age of participants was under 16 years.

Consent for publication: Consent for publication was obtained from the legal guardian of the patients as the age of participants was under 16 years.

Availability of data and materials: The data is part of the PhD thesis of the first authors and can be provided if demand.

Competing interests:

Funding: This research did not receive any specific grant from funding agencies in the public, commercial, or not-for-profit sectors.

\section{Authors' contributions:}

Sara Aslam: Designed the study, collected and analysed the data, prepared tables and figures and wrote the manuscript.

Shabana: Proofread, reviewed and approved the drafts of the paper.

Mehboob Ahmed: Proofread, reviewed and approved the drafts of the paper.

Acknowledgements: Authors would like to acknowledge Dr. Mahwish Faizan, Pediatrician and Oncologist at The Children's Hospital and Institute of Child Health, Lahore, Pakistan for her assistance during blood sample collection.

\section{References}

1. Cancer IAfRo. Global cancer observatory. World Health Organization http://gco iarc fr Accessed. 2018;8.

2. Afzal MS. Childhood Cancer in Pakistan. Iranian Journal of Public Health. 2020.

3. Rabin KR, Poplack DG. Management strategies in acute lymphoblastic leukemia. Oncology. 2011;25(4).

4. Brown AL, De Smith AJ, Gant VU, Yang W, Scheurer ME, Walsh KM, et al. Inherited genetic susceptibility to acute lymphoblastic leukemia in Down syndrome. Blood. 2019;134(15):1227-37. 
5. Sinnett $D$, Krajinovic M, Labuda $D$. Genetic susceptibility to childhood acute lymphoblastic leukemia. Leukemia \& lymphoma. 2000;38(5-6):447-62.

6. Gutierrez-Camino A, Martin-Guerrero I, García-Orad A. Genetic susceptibility in childhood acute lymphoblastic leukemia. Medical Oncology. 2017;34(10):179.

7. Khalid A, Aslam S, Ahmed M, Hasnain S, Aslam A. Risk assessment of FLT3 and PAX5 variants in Bacute lymphoblastic leukemia: a case-control study in a Pakistani cohort. PeerJ. 2019;7:e7195.

8. Jastaniah W. Successful treatment of mature B-cell lymphoma with rituximab-based chemotherapy in a patient with Bloom syndrome. Pediatric Blood \& Cancer. 2017;64(7):e26385.

9. Bener A, El Ayoubi HR, Chouchane L, Ali Al, Al-Kubaisi A, Al-Sulaiti H, et al. Impact of consanguinity on cancer in a highly endogamous population. Asian Pac J Cancer Prev. 2009;10(1):35-40.

10. Zhang J, Walsh MF, Wu G, Edmonson MN, Gruber TA, Easton J, et al. Germline mutations in predisposition genes in pediatric cancer. New England Journal of Medicine. 2015;373(24):2336-46.

11. Knapke S, Nagarajan R, Correll J, Kent D, Burns K. Hereditary cancer risk assessment in a pediatric oncology follow-up clinic. Pediatric blood \& cancer. 2012;58(1):85-9.

12. Jastaniah W, Aljefri A, Ayas M, Alharbi M, Alkhayat N, Al-Anzi F, et al. Prevalence of hereditary cancer susceptibility syndromes in children with cancer in a highly consanguineous population. Cancer epidemiology. 2018;55:88-95.

13. Giri VN, Obeid E, Gross L, Bealin L, Hyatt C, Hegarty SE, et al. Inherited mutations in men undergoing multigene panel testing for prostate cancer: emerging implications for personalized prostate cancer genetic evaluation. JCO Precision Oncology. 2017;1:1-17.

14. Himes DO, Shuman HB. Hereditary Cancer Syndrome Recognition and Testing: Beyond BRCA. The Journal for Nurse Practitioners. 2020.

15. Niendorf KB, Geller MA, Vogel RI, Church TR, Leininger A, Bakke A, et al. A model for patient-direct screening and referral for familial cancer risk. Familial cancer. 2016;15(4):707-16.

16. Caswell-Jin JL, Gupta T, Hall E, Petrovchich IM, Mills MA, Kingham KE, et al. Racial/ethnic differences in multiple-gene sequencing results for hereditary cancer risk. Genetics in Medicine. 2018;20(2):2349.

17. Jastaniah W, Essa MF, Ballourah W, Abosoudah I, Al Daama S, Algiraigri AH, et al. Incidence trends of childhood acute lymphoblastic leukemia in Saudi Arabia: Increasing incidence or competing risks? Cancer epidemiology. 2020;67:101764.

18. Lu KH, Wood ME, Daniels M, Burke C, Ford J, Kauff ND, et al. American Society of Clinical Oncology Expert Statement: collection and use of a cancer family history for oncology providers. Journal of Clinical Oncology. 2014;32(8):833.

19. Bashford MT, Kohlman W, Everett J, Parrott A, Pollin TI. Addendum: a practice guideline from the American College of Medical Genetics and Genomics and the National Society of Genetic Counselors: referral indications for cancer predisposition assessment. Genetics in Medicine. 2019;21(12):2844-. 
20. Fareed M, Afzal M. Genetics of consanguinity and inbreeding in health and disease. Annals of human biology. 2017;44(2):99-107.

21. Zaini R. Sickle-cell anemia and consanguinity among the Saudi Arabian population. Arch Med. 2016;8(3):3-15.

22. Ullah MA, Husseni AM, Mahmood SU. Consanguineous marriages and their detrimental outcomes in Pakistan: an urgent need for appropriate measures. Int J Community Med Public Health. 2017;5(1):13.

23. Baris HN, Barnes-Kedar I, Toledano H, Halpern M, Hershkovitz D, Lossos A, et al. Constitutional mismatch repair deficiency in Israel: high proportion of founder mutations in MMR genes and consanguinity. Pediatric blood \& cancer. 2016;63(3):418-27.

24. Ripperger T, Schlegelberger B. Acute lymphoblastic leukemia and lymphoma in the context of constitutional mismatch repair deficiency syndrome. European journal of medical genetics. 2016;59(3):133-42.

25. Ripperger T, Beger C, Rahner N, Sykora KW, Bockmeyer CL, Lehmann U, et al. Constitutional mismatch repair deficiency and childhood leukemia/lymphoma-report on a novel biallelic MSH6 mutation. Haematologica. 2010;95(5):841-4.

26. Denic S, Bener A. Consanguinity decreases risk of breast cancer-cervical cancer unaffected. British journal of cancer. 2001;85(11):1675-9.

27. Elalaoui SC, Jaouad IC, Laarabi FZ, Elgueddari Bel K. Low level of consanguinity in moroccan families at high risk of breast cancer. Asian Pac J Cancer Prev. 2013;14(2):723-6.

28. Hampel H, Stephens JA, Pukkala E, Sankila R, Aaltonen LA, Mecklin J-P, et al. Cancer risk in hereditary nonpolyposis colorectal cancer syndrome: later age of onset. Gastroenterology. 2005;129(2):415-21.

29. Magdy T, Burmeister BT, Burridge PW. Validating the pharmacogenomics of chemotherapy-induced cardiotoxicity: what is missing? Pharmacology \& therapeutics. 2016;168:113-25.

30. Yang X, Li G, Yang T, Guan M, An N, Yang F, et al. Possible Susceptibility Genes for Intervention against Chemotherapy-Induced Cardiotoxicity. Oxidative Medicine and Cellular Longevity. 2020;2020.

31. Soegaard M, Jensen A, Frederiksen K, Høgdall E, Høgdall C, Blaakær J, et al. Accuracy of selfreported family history of cancer in a large case-control study of ovarian cancer. Cancer Causes \& Control. 2008;19(5):469-79.

32. Ozanne EM, O'Connell A, Bouzan C, Bosinoff P, Rourke T, Dowd D, et al. Bias in the reporting of family history: implications for clinical care. Journal of genetic counseling. 2012;21(4):547-56.

\section{Figures}




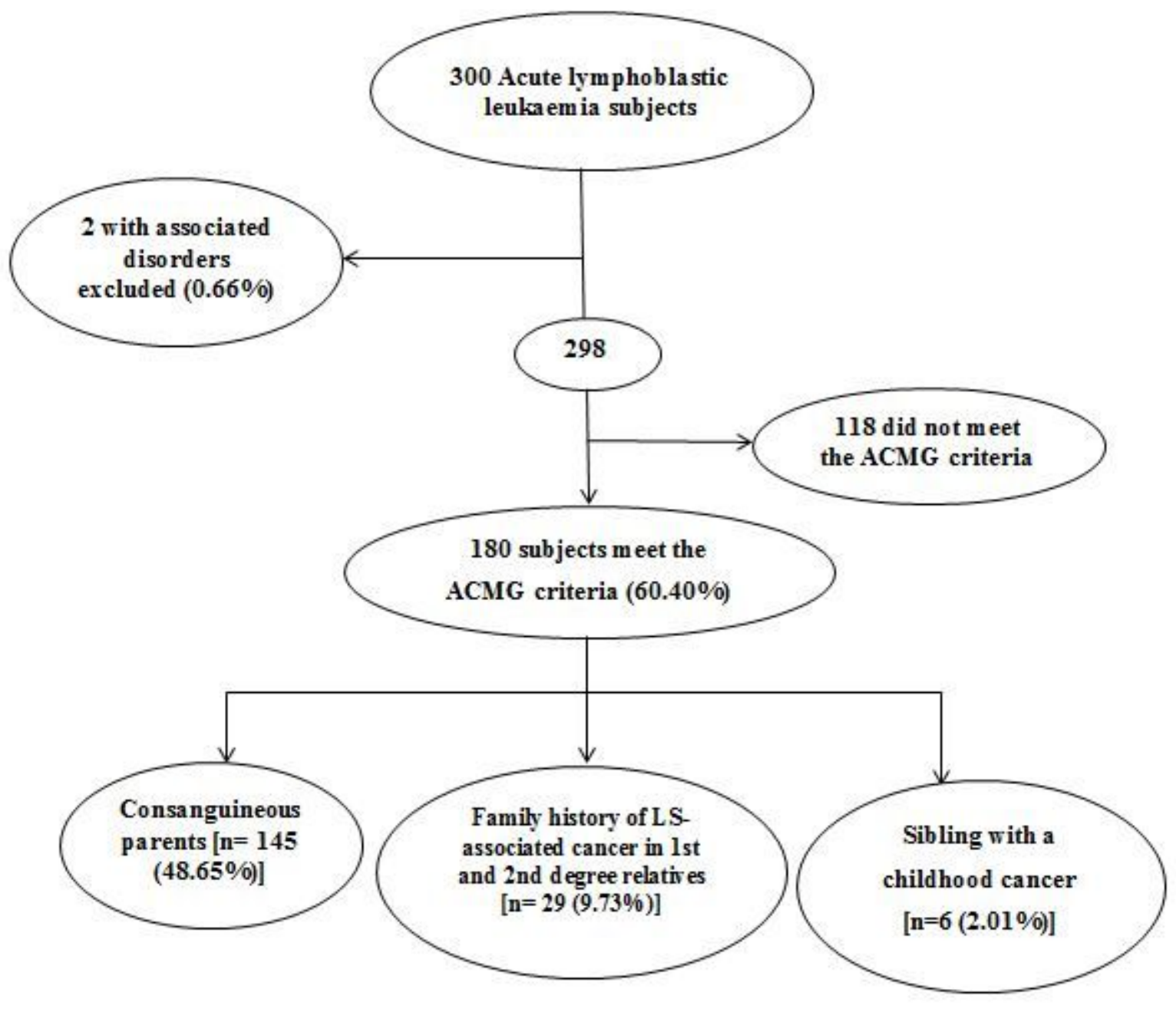

Figure 1

Consort diagram showing the selection of ALL patients with HCSS by using ACMG guidelines. 